\title{
A one year follow up study of persistent motor tic disorder treated with risperidone in a children's hospital in Sri Lanka
}

\author{
*Miyuru Chandradasa ${ }^{1}$, Darshani Hettiarachchi ${ }^{2}$, Yasodha Rohanachandra ${ }^{2}$, Swarna Wijetunge $^{3}$
}

Sri Lanka Journal of Child Health, 2017; 46(2): 133-138

\begin{abstract}
Introduction: Transient tics are common in children. In persistent motor tic disorders, single or multiple motor tics persist for more than a year.
\end{abstract}

Objective: To determine the one year outcome of persistent motor tic disorder treated with risperidone in a group of Sri Lankan children.

Method: New patients presenting to the Child and Adolescent Mental Health Services of the Lady Ridgeway Hospital for Children in Colombo were screened for tics. Diagnosis was made by a consultant psychiatrist according to the Diagnostic and Statistical Manual of mental disorders $5^{\text {th }}$ edition (DSM-5). The children were prospectively followed up for a period of one year with monthly assessments. Patients treated solely with oral risperidone from the beginning were analysed. In all children dose of risperidone ranged from $0.25-2 \mathrm{mg} / \mathrm{day}$. Of all children with tics, only children with persistent motor tic disorder were included in the follow up. The symptom severity was measured using the Yale Global Tic Severity Scale (YGTSS). A reduction of the YGTSS score by 35\% was considered as a satisfactory response to treatment. The presence of comorbid psychiatric disorders was assessed clinically as well as by using the Swanson, Nolan and Pelham teacher and parent rating scale $4^{\text {th }}$ version and Yale Brown obsessive compulsive scale. Ethical approval was obtained from the ethics review committee of the Lady Ridgeway Hospital.

${ }^{1}$ Lecturer in Psychiatry, Faculty of Medicine, University of Kelaniya, ${ }^{2}$ Senior Registrar in Child \& Adolescent Psychiatry, Lady Ridgeway Hospital for Children, Colombo, ${ }^{3}$ Consultant Psychiatrist, Lady Ridgeway Hospital for Children, Colombo, Sri Lanka *Correspondence: miyuruc@kln.ac.lk

(Received on 24 July 2016: Accepted after revision on 23 September 2016)

The authors declare that there are no conflicts of interest

Personal funding was used for the project.

Open Access Article published under the Creative

Commons Attribution CC-BY (CC) (i)
Results: Of the screened patients, 123 children were diagnosed with a persistent motor tic disorder at the beginning of the study. Of these, 17 were excluded because of irregular attendance at the monthly assessments and 3 were excluded as the diagnosis was changed to Tourette syndrome due to the detection of new symptoms. Eye blinking and shoulder shrugging were the commoner tic types in participants. Attention deficit hyperactivity disorder was the commonest comorbid psychiatric disorder. After 12 months follow up, $78.6 \%$ of participants responded to risperidone with a predefined $35 \%$ lessened tic severity score according to the YGTSS. The percentage of children with comorbid ADHD who had responded to risperidone at $35 \%$ YGTSS score reduction was significantly low compared to the children without $\operatorname{ADHD}(p<0.05)$. There was no statistically significant difference in the treatment response according to age, gender, complexity of tics or type of tics.

Conclusions: After one year follow up, $79 \%$ of children with persistent motor tic disorder responded satisfactorily to risperidone. The percentage of children with comorbid ADHD who responded satisfactorily to risperidone was significantly low compared to the children without ADHD $(\mathrm{p}<0.05)$.

DOI: http://dx.doi.org/10.4038/sljch.v46i2.8269

(Key words: Tic disorders, treatment outcome, followup)

\section{Introduction}

A tic is defined as a sudden, rapid, recurrent, nonrhythmic motor movement or vocalization according to the $5^{\text {th }}$ edition of the Diagnostic and Statistical Manual of mental disorders (DSM-5) ${ }^{1}$. There are several types of tic disorders according to this classification ${ }^{1}$. Tourette disorder is diagnosed in the presence of multiple motor tics and one or more vocal tics for a duration of more than a year ${ }^{1}$. Persistent tic disorder is where single or multiple motor tics or vocal tics have been present for more than a year ${ }^{1}$. The final category is the provisional tic disorder in which single or multiple motor and/or vocal tics have persisted for a period less than a year ${ }^{1}$. In all of the above categories the onset should be before the age of 18 years ${ }^{1}$. 
Transient tics in children are common. In a review of community surveys, $20 \%$ of school children were detected to have transient tics ${ }^{2}$. Many of these transient tics are time limited and may not require specific treatment. On the other hand, persistent motor tic disorders are disorders with single or multiple motor tics persisting for more than a year ${ }^{1}$. In a large study conducted in Brazil, $2.9 \%$ of about 10,000 participants had tic disorders and $78 \%$ of them had persistent tic disorder $(2.3 \%)^{3}$.

There have been case reports of Tourette disorder and tics in the presence of beta haemolytic streptococcal infection from Sri Lanka ${ }^{4,5}$. In addition, a study done among children diagnosed with attention deficit hyperactivity disorder in Sri Lanka found that 2.5\% of them suffer from comorbid tics ${ }^{6}$. However, we could not find any other published studies on Sri Lankan children suffering from tic disorders.

Studies on treatment outcome of tic disorders are limited worldwide, even more for the South Asian region. When considering the few follow up studies on tic disorders from the West, majority of these were conducted on patients with Tourette disorder rather than persistent motor tic disorder. In a follow up of five years of patients with Tourette disorder, $22 \%$ of participants were detected to have worsened symptoms, while $13 \%$ improved $^{7}$. The treatment response to risperidone in children with tic disorders has not been studied in Sri Lanka.

\section{Objective}

The objective of our study was to find the one year outcome of persistent motor tic disorder treated with the second generation antipsychotic risperidone in a group of Sri Lankan children.

\section{Method \\ The study was conducted as an observational analytical study. A screening was done for the presence of tics among new patients presenting to the Child and Adolescent Mental Health Services of the Lady Ridgeway Hospital for Children in Colombo. After a detailed clinical assessment of each child, the diagnosis was achieved by a consultant psychiatrist according to the Diagnostic and Statistical Manual of mental disorders $5^{\text {th }}$ edition (DSM-5) ${ }^{1}$. The sampling process is depicted in figure 1.}

\section{All children presenting to the outpatient clinic}

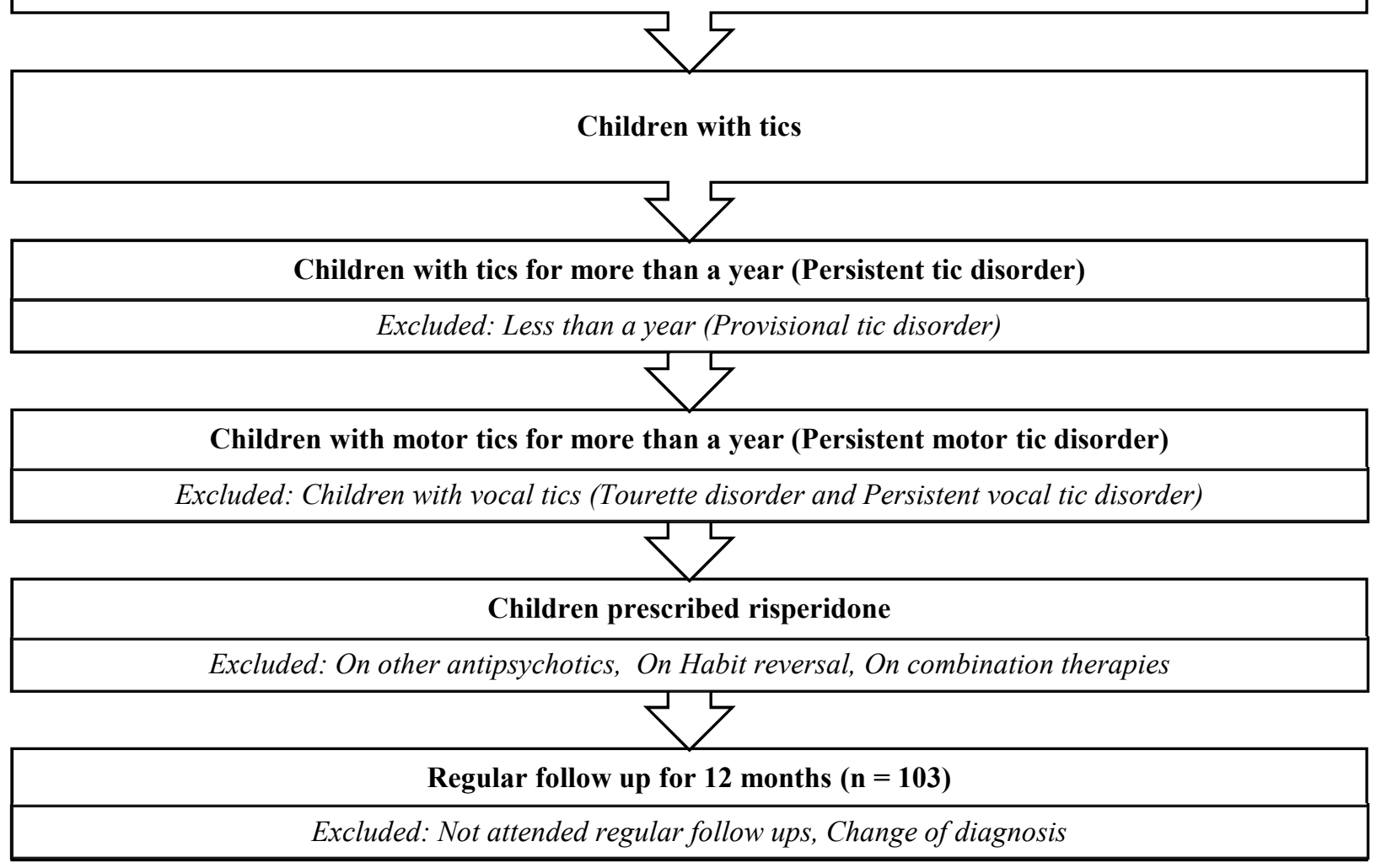

Figure 1: The sampling process 
The children were prospectively followed up for a period of one year with monthly assessments. Only patients treated solely with oral risperidone at the beginning were considered for the analysis. The children who were treated with habit reversal therapy and combinations of treatments were excluded to maintain the uniformity of the cohort. Furthermore, out of all children with tics, children with persistent motor tic disorder were included in the follow up. The children who had symptoms for less than 12 months at the beginning of the study were diagnosed as provisional tic disorder and were excluded. Also, any child who had a change in their diagnosis during the course of the follow up to Tourette disorder was removed from the study sample.

Children with persistent vocal tic disorder were not considered for the follow up. This measure was taken due to several reasons. Firstly, there is a difficulty in detecting children with vocal tics as many parents fail to identify this phenomenon as a symptom and may deny its presence during the clinical interview. Secondly, there were only a few children with vocal tics and the authors decided to keep the cohort as uniform as possible by including only children with persistent motor tic disorder. Thirdly, as vocal tics are a key symptom of Tourette disorder, some children identified as persistent vocal tic disorder at the initiation later developed Tourette disorder ${ }^{1}$. Even though this is true even for persistent motor tic disorder, there were higher numbers of children to be followed up with motor tics alone.

In all children, the commencing dose of risperidone was $0.25 \mathrm{mg}$ and the dose ranged from $0.25-2 \mathrm{mg} /$ day. The symptom severity was measured using the Yale Global Tic Severity Scale (YGTSS), which is an interviewer administered structured assessment tool ${ }^{8}$. This scale has provisions to assess both motor and vocal tics. For each type of tic there are several components to determine the severity. The severity is decided by number of tics, frequency, intensity, complexity and interference to behaviour of the child scored $0-5$ for each component. Therefore a score would be obtained from 0-25 each for motor and vocal tics. Combination of these two scores is the total tic severity score which is given from 0-50. Further assessment is done on functioning and the impairment is rated from 0-50. After addition of the total tic severity score and impairment score, the total score is given from $0-100$. A reduction of the YGTSS total tic severity score by $35 \%$ was considered as a satisfactory response to treatment as suggested by previous studies $^{9,13}$. Any child who was commenced on habit reversal therapy, change in antipsychotic or combination treatments during the one year follow up were considered as an unsatisfactory response to risperidone in the analysis.

The presence of comorbid psychiatric disorders was assessed clinically and using structured tools. The symptoms of attention deficit hyperactivity disorder (ADHD) were determined using the Swanson, Nolan and Pelham teacher and parent rating scale $4^{\text {th }}$ version $(\text { SNAP IV })^{10}$. The 18 item version which was used, has the ability to detect symptoms of inattention, hyperactivity and impulsivity in the child. The tool used to assess symptoms of obsessive compulsive disorder (OCD) was the children's Yale Brown Obsessive Compulsive Scale (YBOCS) ${ }^{11}$. This scale has mainly two components for obsessions and compulsions. Furthermore, the children were assessed clinically for the presence of comorbidities such as specific learning disorder, intellectual disability and conduct disorder according to the DSM- $5^{1}$.

There are some reports of worsening of tics when comorbid ADHD symptoms are treated with stimulant medications such as methylphenidate ${ }^{12}$. Even though recent studies dispute these claims, the participants of this study with comorbid ADHD symptoms were treated with non-stimulant medications such as clonidine $^{12}$. Ethical approval was obtained from the ethics review committee of the Lady Ridgeway hospital. Written informed consent was obtained from a parent and assent from all the participants. The children recruited to the study were already commenced on risperidone. Participation in the study did not affect the management decisions at any stage of the follow up.

\section{Results}

Out of the screened patients, 123 children were diagnosed with a persistent motor tic disorder at the beginning of the study. Among these, 17 did not attend regularly to complete the monthly assessments for the stipulated period of 12 months. In three children the diagnosis was changed to Tourette syndrome due to the detection of new symptoms. The 103 children who completed the one year follow up were considered for the analysis.

The mean age of participants was $8.9 \pm 2.9$ years. Boys comprised $73 \%$ of the followed up sample. Majority (74\%) of the participants had only simple tics. There was a family history of tic disorder in a first degree relative in $11 \%$ of children studied. Eye blinking was the commonest type of tic followed by shrugging of shoulders as shown in table 1 . 
Table 1

Number and common types of tics in participant children with persistent tic disorder $(n=103)$

\begin{tabular}{|l|c|}
\hline Characteristic & Number (\%) \\
\hline Number of tics & \\
Single & $51(49.5)$ \\
Multiple & $52(50.5)$ \\
\hline Type of tics & \\
Eye blinking & $53(51.4)$ \\
Shoulder shrugging & $28(27.1)$ \\
Hand movements & $19(18.4)$ \\
\hline
\end{tabular}

ADHD was the commonest comorbid psychiatric disorder followed by specific learning disorder as shown in table 2. The response to risperidone is shown in table 3.

Table 2

Types of comorbid psychiatric disorders in children with persistent tic disorder $(n=103)$

\begin{tabular}{|l|c|}
\hline \multicolumn{1}{|c|}{ Psychiatric comorbidity } & Number (\%) \\
\hline $\begin{array}{l}\text { Attention deficit hyperactivity } \\
\text { disorder }\end{array}$ & $49(47.5)$ \\
\hline Specific learning disorder & $26(25.2)$ \\
\hline Obsessive compulsive disorder & $12(11.6)$ \\
\hline Conduct disorder & $10(09.7)$ \\
\hline $\begin{array}{l}\text { Intellectual developmental } \\
\text { disorder }\end{array}$ & $09(08.7)$ \\
\hline
\end{tabular}

*Some children had more than one comorbidity

Table 3: Response of persistent motor tic disorder to risperidone according to comorbidities

\begin{tabular}{|l|c|c|}
\hline \multicolumn{1}{|c|}{ Comorbidity group } & Number with a 35\% reduction of the total tic severity score (\%) & P value \\
\hline Total participants & $81(78.6)$ & \\
\hline ADHD & $33(67.7)$ & 0.015 \\
\hline Specific learning disorder & $17(65.4)$ & 0.103 \\
\hline OCD & $08(66.6)$ & 0.483 \\
\hline Conduct disorder & $07(70.0)$ & 0.767 \\
\hline Intellectual disability & $09(100)$ & 0.226 \\
\hline
\end{tabular}

At 12 months of follow up, $78.6 \%$ of all the participants responded to risperidone with a predefined $35 \%$ lessened tic severity score according to the YGTSS ${ }^{8,9}$. The percentage of children with comorbid ADHD who had responded to risperidone at $35 \%$ YGTSS total tic severity score reduction was significantly low compared to the children without ADHD. There was no statistically significant difference in the treatment response according to the age, gender, complexity of tics and type of tics. The mean dose of risperidone per day used at the end of follow up period was $1.17 \mathrm{mg}(\mathrm{SD}=0.617)$ for all the participants. The risperidone mean dose in participants who had a responded was $1.19 \mathrm{mg} /$ day $(\mathrm{SD}=0.617)$ at the end of 12 months follow up. This was not significantly different from the mean value for the non-responders, which was $1.09 \mathrm{mg} /$ day $(\mathrm{SD}=0.625)$ $(\mathrm{t}=0.696, \mathrm{P}=0.488)$. The commonest reported adverse effects for risperidone were day time sedation (41\%), followed by weight gain (29\%).

\section{Discussion}

The main finding of this study is that risperidone is effective in reducing symptoms in persistent motor tic disorder in the participating children. There are only a few published studies on persistent tic disorders per se treated with risperidone. In a small study conducted in Korea a 36\% reduction of the YGTSS score was seen among 13 out of 15 participants at six weeks duration ${ }^{13}$. This study also included patients with Tourette disorder apart from children with persistent motor tic disorder. The scarcity of follow up studies on persistent motor tic disorder for South Asia makes the comparison of results of this study difficult. But when considering studies from the West there are several conducted on children with all types of tic disorder showing high response rates ${ }^{14}$.

Among the majority of participants in our study, treatment with risperidone was associated with a satisfactory treatment response during the follow up. In the context of limited neuropsychiatric treatment facilities for children in Sri Lanka, risperidone appears to be an effective management option for persistent motor tic disorder. There was no significant difference in the mean risperidone dose of the responders and non-responders. Despite the study participants were given relatively low doses of risperidone (mean $=1.17$ $\mathrm{mg} /$ day), a majority $(79 \%)$ achieved the predefined level of reduction of symptoms. A previous randomized controlled trial comparing risperidone to aripiprazole in children with tics found that risperidone was effective at a mean dose of 0.6 $\mathrm{mg} / \mathrm{day}^{14}$. It is important to maintain the doses of antipsychotics in children at a minimum effective level as there have been reports of serious adverse effects to antipsychotics in children with neurodevelopmental disorders from Sri Lanka ${ }^{15}$. Further studies are warranted to explore the treatment response for other forms of therapy such as habit reversal therapy and combination therapies in Sri Lankan children with persistent motor tic disorder. 
The treatment response of the children with comorbid ADHD was found to be less compared to the children without ADHD. The children with comorbid ADHD were treated with clonidine for their inattention, hyperactivity and impulsivity symptoms. Clonidine is known to be effective in reducing tics as well ${ }^{16}$. The use of this medication could have had an effect on the tics itself, in addition to the risperidone which was the focus of the study. Nevertheless the treatment response in this group was significantly less than in children without ADHD.

The treatment response of participating children with other comorbidities such as specific learning disorder and OCD were not significantly different from the participants without these comorbidities. This could be due to the fact that the number of children with these comorbidities were low, leading to low statistical power when assessing the significance. Otherwise this might mean that these comorbidities do not genuinely affect the response to risperidone. Nonetheless the significance of comorbidities such as specific learning disorder and intellectual disability is immense as they are known to impact on the academic achievements of the relevant child during their childhood and adulthood $^{17}$.

In our opinion one of the key achievements of this study is to follow up a cohort of children with persistent motor tic disorder for a period of 12 months on a regular basis. Many published studies, mainly from the West, have studied smaller numbers of children for briefer periods. The diagnosis of the child was revaluated on each clinic visit and any change of symptoms was closely assessed. This was done to keep the uniformity of the cohort high, in order to obtain more relevant and valid results. A weakness was that this was not a clinical trial and there was no randomization of recruits or a control group. A control group would have allowed assessment of the effectiveness of risperidone compared to other pharmacotherapies and psychotherapies in Sri Lankan children with persistent motor tic disorder. Nevertheless, other recommended pharmacotherapies such as aripiprazole are far more expensive and are not available in the free government health service of the country ${ }^{14}$. Furthermore, habit reversal which is the psychotherapy used for tic disorders requires many hours for an individual child and might not be feasible in the Sri Lankan health setting where the experts to child ratio is low ${ }^{18}$.

\section{Conclusions}

- After one year follow up, $79 \%$ of children with persistent motor tic disorder responded satisfactorily to risperidone.

- The percentage of children with comorbid ADHD who responded satisfactorily to risperidone was significantly low compared to the children without ADHD $(\mathrm{p}<0.05)$.

\section{References}

1. American Psychiatric Association. Diagnostic and Statistical Manual of Mental Disorders (DSM-5®) Psychiatric Publishing, Arlington, Virginia 2013.

2. Scahill L, Specht M, Page C. The prevalence of tic disorders and clinical characteristics in children. Journal of Obsessive-Compulsive and Related Disorders 2014; 3(4):394-400. https://doi.org/10.1016/j.jocrd.2014.06.002 PMid: 25436183 PMCid: PMC4243175

3. Alves HL, Quagliato EM. The prevalence of tic disorders in children and adolescents in Brazil. Arq Neuropsiquiatr. 2014; 72(12): 942-8.

https://doi.org/10.1590/0004-282X20140174 PMid: 25465775

4. Perera H, Abayanayaka C. Management of severe paediatric Tourette syndrome resistant to drug treatment. Case Reports in Psychiatry 2012; 2012:497160.

https://doi.org/10.1155/2012/497160

PMid: 23047460 PMCid: PMC3461628

5. Perera H, Weerasinghe M, Sathiadas G. Two cases of paediatric autoimmune neuropsychiatric disorder associated with group A beta haemolytic streptococcal infection. Sri Lanka Journal of Child Health 2010; 39(1): 29-30. https://doi.org/10.4038/sljch.v39i1.1633

6. Wijetunge G, Dayasena J, Kulathilake I, Ratnathilake P, Namasivayam Y. Prevalence of comorbidities in children with attention deficit and hyperactivity disorder at Lady Ridgeway Hospital for Children, Sri Lanka. Sri Lanka Journal of Child Health 2015; 44(2):77. https://doi.org/10.4038/sljch.v44i2.7988 
7. de Groot CM, Bornstein RA, Spetie L, Burriss B. The course of tics in Tourette syndrome: a 5-year follow-up study. Annals of Clinical Psychiatry 1994; 6(4):227-33. https://doi.org/10.3109/10401239409149009 PMid: 7647832

8. Leckman JF, Riddle MA, Hardin MT, Ort SI, Swartz KL, Stevenson J, Cohen DJ: The Yale Global Tic Severity Scale: initial testing of a clinician-rated scale of tic severity. Journal of the American Academy of Child and Adolescent Psychiatry 1989; 28(4):566-73. https://doi.org/10.1097/00004583198907000 $-00015$

PMid: 2768151

9. Storch EA, De Nadai AS, Lewin AB, McGuire JF, Jones AM, Mutch PJ. Defining treatment response in paediatric tic disorders: a signal detection analysis of the Yale Global Tic Severity Scale. Journal of Child and Adolescent Psychopharmacology 2011; 21(6):621-7.

https://doi.org/10.1089/cap.2010.0149

PMid: 22070181 PMCid: PMC3279714

10. Atkins MS, Pelham WE, Licht MH: A comparison of objective classroom measures and teacher ratings of attention deficit disorder. Journal of Abnormal Child Psychology 1985; 13(1):155-67 https://doi.org/10.1007/BF00918379

11. Goodman WK, Price LH, Rasmussen SA, Mazure C, Delgado P, Heninger GR, et al. The Yale-Brown Obsessive Compulsive Scale. II. Validity. Archives of General Psychiatry 1989; 46 (11):1012-6. https://doi.org/10.1001/archpsyc.1989.01810 110054008

PMid: 2510699

12. Pringsheim T, Steeves T. Pharmacological treatment for Attention Deficit Hyperactivity Disorder (ADHD) in children with comorbid tic disorders. Cochrane Database of Systematic Reviews 2011; 13(4):CD001735. https://doi.org/10.1002/14651858.cd007990. pub2

13. Kim BN, Lee CB, Hwang JW, Shin MS, Cho $\mathrm{SC}$. Effectiveness and safety of risperidone for children and adolescents with persistent tic or Tourette disorders in Korea. Journal of Child and Adolescent Psychopharmacology 2005; 15(2):318-24.

https://doi.org/10.1089/cap.2005.15.318

PMid: 15910216

14. Ghanizadeh A, Haghighi A. Aripiprazole versus risperidone for treating children and adolescents with tic disorder: a randomized double blind clinical trial. Child Psychiatry Hum Dev. 2014 Oct;45(5):596-603. https://doi.org/10.1007/s10578-013-0427-1 PMid: 24343476

15. Chandradasa M, Kotalawala S, Siriwardene G, Champika L, Seneviratne S, Perera H. Tardive dyskinesia in an 8-year old child. Sri Lanka Journal of Psychiatry. 2014 Dec; 5(2), pp.24-26.

https://doi.org/10.4038/sljpsyc.v5i2.7819

16. Pringsheim T, Steeves T. Pharmacological treatment for Attention Deficit Hyperactivity Disorder (ADHD) in children with comorbid tic disorders. Cochrane Database of Systematic Reviews 2011; 13(4):CD007990. https://doi.org/10.1002/14651858.cd007990. pub2

17. Weis R, Speridakos EC, Ludwig K. Community college students with learning disabilities: evidence of impairment, possible misclassification, and a documentation disconnect. Journal of Learning Disabilities 2014; 47(6):556-68. https://doi.org/10.1177/0022219413483175 PMid: 23545450

18. Kitsiri R. Policy Study Report: financing public health care in Sri Lanka. Basic Needs International, 2009 